\title{
CONSTRUÇÃO DA IDENTIDADE INTERSECCIONAL: UMA ANÁLISE CRÍTICA DO DISCURSO SOBRE MUDANÇAS SOCIAIS E DISCURSIVAS DE/PARA MULHERES SURDAS
}

\section{CONSTRUCTION OF INTERSECTIONAL IDENTITY: A CRITICAL DISCOURSE ANALYSIS ON SOCIAL AND DISCURSIVE CHANGES OF/FOR DEAF WOMEN}

Cleide Emília Faye Pedrosa ${ }^{1}$

\begin{abstract}
RESUMO
A discussão sobre o papel das mulheres ocupa, gradativamente, ao longo das últimas décadas, lugar de compromissos em agendas governamentais e acadêmicas (FONTANA; FERRARI, 2017). Leis, decretos, programas sociais e também projetos acadêmicos têm respondido a esse pleito. Todos esses compromissos originam mudanças sociais e são, ao mesmo tempo, também resultados de mobilizações das minorias sociais que são muito bem trabalhadas pela base teórica da Análise Crítica do Discurso (FAIRCLOUGH, 2008; RESENDE, 2017), especialmente por sua corrente brasileira - a Abordagem Sociológica e Comunicacional do Discurso - ASCD (PEDROSA, 2018). Nossas pesquisas na UFRN e na UFS (respectivamente Universidade Federal do Rio Grande do Norte e Universidade Federal de Sergipe), esta onde trabalho atualmente, foram, há 6 anos, direcionadas para grupos vulneráveis, entre eles a comunidade surda; assim, a partir de corpus formado por narrativas de vida e texto introdutório do Currículo Lattes dessa comunidade, selecionaremos um exemplo de cada gênero, especificamente de mulheres Surdas, a fim de proceder à análise com base metodológica da pesquisa qualitativa-interpretativista. Ainda como caminhos de análise, utilizaremos a proposta da socioanálise oriunda da Sociologia para a Mudança Social - SMS - (BAJOIT, 2013). Os resultados pretendem atingir o objetivo geral de verificar de que forma as narrativas de vida e o texto introdutório do Currículo Lattes demonstram os desenganos e as vitórias da mulher Surda quanto à constituição interseccional de sua identidade no contexto da história de sua educação.
\end{abstract}

PALAVRAS-CHAVE: Mulheres Surdas; Identidade Interseccional; Análise Crítica do Discurso.

\begin{abstract}
The discussion about the role of women has gradually occupied a place of commitments of governmental and academic agendas over the last decades (FONTANA; FERRARI, 2017). Laws, decrees, social programs and also academic projects have responded to this issue. All these commitments lead to social changes, and they are also the results of mobilizations of social minorities that are focus of the theoretical basis called Critical Discourse Analysis [CDA] (FAIRCLOUGH, 2008; RESENDE, 2017) as well as the Brazilian approach to CDA - Abordagem Sociologica e Comunicacional do Discurso - ASCD (PEDROSA, 2018). Our research at UFRN and UFS (respectively Federal University of Rio Grande do Norte and Federal University of Sergipe), this where I currently work, aimed at vulnerable groups for 6 years, and among them, the deaf community. So, from a corpus formed by life narratives and the introductory text of the curriculum lattes of this community, we will select an example of each gender, specifically, deaf women, in order to proceed with the methodological basis of the qualitative-interpretive research. For the analyses, we will work with the socioanalysis based on the Sociologia para a Mudança Social - SMS (BAJOIT, 2013). The results aim to achieve the general objective of verifying how the life narratives
\end{abstract}

\footnotetext{
${ }^{1}$ Doutora em Letras pela Universidade Federal de Pernambuco (2005), Pós-Doutorado em Letras pela Universidade do Estado do Rio de janeiro, 2008, docente nos cursos de Letras e Letras Libras e no PPGL da UFS.
} 
and the introductory text of the curriculum lattes show the disillusionment and victories of/for the deaf woman as to the intersectional constitution of her identity in the context of the history of her education.

KEYWORDS: Deaf Women; Intersectional Identities; Critical Discourse Analysis.

\section{INTRODUÇÃO}

$\mathrm{Na}$ atualidade, podemos identificar uma forte discussão sobre grupos vulneráveis que tem movido a agenda governamental e de várias propostas acadêmicas. A questão das mulheres, por muito tempo silenciada, ocupa, gradualmente, ao longo das últimas décadas, lugar de compromissos nessas agendas (FONTANA; FERRARI, 2017). Todos esses compromissos originam mudanças sociais e são, ao mesmo tempo, também resultados de mobilizações de grupos minoritários que são muito bem trabalhadas pela base teórica da Análise Crítica do Discurso (FAIRCLOUGH, 2008; RESENDE, 2017), especialmente através da corrente brasileira, fundada por Pedrosa em 2011 - a Análise Sociológica e Comunicacional do Discurso - ASCD (PEDROSA, 2016, 2018).

As pesquisas desenvolvidas na UFRN e na UFS (respectivamente Universidade Federal do Rio Grande do Norte e Universidade Federal de Sergipe), esta onde trabalho atualmente, são direcionadas para grupos vulneráveis, entre eles a comunidade Surda ${ }^{2}$, com a qual trabalho há seis anos; assim, a partir de corpus formado por narrativas de vida e texto introdutório do Currículo Lattes dessa comunidade, selecionaremos um exemplo de cada gênero, especificamente de mulheres surdas, a fim de proceder à análise com base metodológica da pesquisa qualitativainterpretativista. Como percurso de análise, utilizaremos a proposta da socioanálise advinda da Sociologia para a Mudança Social - SMS - (BAJOIT, 2012). Os resultados pretendem atingir o objetivo geral de verificar de que forma as narrativas de vida e o texto introdutório do Currículo Lattes demonstram os desenganos e as vitórias da mulher surda quanto à constituição interseccional de sua identidade no contexto da história de sua educação.

O desenho do texto apresenta os seguintes tópicos: Análise Crítica do Discurso e engajamento de pesquisa com os grupos vulneráveis, dando destaque à mulher surda; uma breve apresentação da ASCD, contemplando a socioanálise e a mudança social; um tópico analítico, considerando as mulheres surdas brasileiras e as práticas de resistências em sua educação para a constituição de sua identidade interseccional; e, finalmente, alguns aspectos conclusivos.

\section{Análise Crítica do Discurso e engajamento de pesquisa com os grupos vulneráveis}

A Análise Crítica do Discurso ou Análise de Discurso Crítica se configura como uma área de estudo que se compromete politicamente em favor dos grupos vulneráveis que lutam por seus direitos. Assim, os pesquisadores fazem questão de desenvolver projetos solidários, ou seja, que se engajem socialmente com os grupos que trazem marcas de injustiças sociais.

Opressões interseccionais fazem parte do grupo com o qual objetivamos trabalhar neste estudo: mulheres Surdas. Duas características de vulnerabilidade, como já explicitado, marcam esses sujeitos, "ser mulher" e "ser Surda". Mougeolle (2015), socióloga francesa, aclara que o conceito de interseccionalidade foi usado, primeiramente, em 1991, nos Estados Unidos, pela jurista Kimberlé Williams Crenshaw, uma feminista especializada em assuntos de raça e de gênero. Outros termos que já foram empregados por outros pesquisadores são: "interconectividade" ou "identidades multiplicativas". O conceito situa-se na área da Sociologia e estuda as interações que ocorrem na vida das minorias, dos grupos vulneráveis, envolvendo diferentes estruturas de poder,

\footnotetext{
${ }^{2}$ Costuma-se empregar Surdo e Surda com maiúsculo para indicar uma identidade social e não uma indicação biológica, médica.
} 
e aqui estará sendo utilizado na intersecção de ser mulher e de ser Surda. Não tenho conhecimento se outros estudos na área dos Estudos Surdos utilizaram esse tipo de intersecção.

"Ser mulher", em praticamente todas as sociedades, foi sempre sinônimo de subserviência, tanto que a ONU, em 2010, cria a ONU Mulheres e se pronuncia com os "Princípios de Empoderamento das Mulheres". Estes princípios são algumas considerações que orientam a comunidade empresarial (e válido para outras esferas) a valorizar práticas que busquem a equidade de gêneros, como também na direção de empoderar as mulheres. A seguir, apresentamos os sete Princípios de Empoderamento das Mulheres ${ }^{3}$ :

1. Estabelecer liderança corporativa sensível à igualdade de gênero, no mais alto nível.

2. Tratar todas as mulheres e homens de forma justa no trabalho, respeitando e apoiando os direitos humanos e a não-discriminação.

3. Garantir a saúde, a segurança e o bem-estar de todas as mulheres e homens que trabalham na empresa.

4. Promover educação, capacitação e desenvolvimento profissional para as mulheres.

5. Apoiar empreendedorismo de mulheres e promover políticas de empoderamento das mulheres através das cadeias de suprimentos e marketing.

6. Promover a igualdade de gênero através de iniciativas voltadas à comunidade e ao ativismo social.

7. Medir, documentar e publicar os progressos da empresa na promoção da igualdade de gênero.

A ONU mulheres agrega também os seguintes setores:

Divisão para o Avanço das Mulheres (DAW); Instituto Internacional de Pesquisas e Capacitação para o Progresso da Mulher (INSTRAW); Escritório de Assessoria Especial para Questões de Gênero e Promoção da Mulher (OSAGI); Fundo de Desenvolvimento das Nações Unidas para a Mulher (UNIFEM) (NORONHA, 2017, p. 25-26).

No Brasil, a Secretaria de Políticas para as Mulheres (SPM) foi criada em 2003. É um órgão da Presidência da República e apresenta como objetivo basilar: "promover a igualdade entre homens e mulheres e combater todas as formas de preconceito e discriminação herdadas de uma sociedade patriarcal e excludente". Sua luta é por posições mais justas, democráticas, equitativas, buscando a valorização da mulher através de sua inclusão no processo de desenvolvimento em todos os âmbitos: econômico, social, político e cultural.

Essa secretaria, em março de 2016, realizou uma Consulta Nacional com o objetivo de verificar as principais necessidades das mulheres deficientes. Perlin e Vilhalva (2016), professoras e escritoras Surdas, participantes da convocação, relatam alguns dados, dentre os quais os resumidos a seguir, mais especificamente de 1-3, a fim de acompanhar o "Ser mulher Surda".

As circunstâncias foram elencadas a partir do nascimento da menina Surda que, na maioria dos casos, fica trancafiada em casa, sem nenhuma ou pouca visibilidade social; outras vezes, esse confinamento envolve superproteção da família. Num caso ou noutro, os prejuízos são enormes. Este aspecto é mais acentuado com as Surdas da zona rural, visto que elas, lamentavelmente, ficam sem acesso à educação e ao trabalho. E, mesmo quando recebem educação, esta tende à inferiorização delas.

"Muitas vezes a sociedade continua com a educação colonialista sobre a mulher surda sem noção de sua diferença”, enfatizam Perlin e Vilhalva (2016, s/p). Não há reconhecimento de sua língua e de sua cultura. Não há (re)conhecimento, nem a busca por conhecer, o que é uma mulher Surda. Assim, "Os relatos de experiências tristes se acumulam" e "a falta de tradução para a língua de sinais acontece em diversos espaços, como na saúde, na educação, no trabalho, no espaço de

\footnotetext{
${ }^{3}$ Disponível em: http://www.onumulheres.org.br/referencias/principios-de-empoderamento-das-mulheres/. Acesso em: 09 out. 18.
} 
segurança, enfim, na sua trajetória de vida" (PERLIN; VILHALVA, 2016, s/p). E mais alguns fragmentos de histórias são trazidos pelas autoras:

1- "eu não tenho intérprete quando estou... eu tenho que ir junto com minha mãe na consulta e ela sabe sobre minha doença, eu não sei nunca porque ela resume tudo que ouve",

2- "o meu filho estuda na integração e, como mãe, não tenho intérprete nas reuniões, me sinto como peixe fora da água",

3- "o marido me batia no casamento anterior porque eu não o entendia", "como ligar para a delegacia da mulher, lá não tem intérprete, comunicação por vídeo, nada para nós que usamos libras".

As autoras acreditam que a mulher Surda está sendo alfabetizada cada vez mais tarde, assim são alunas que engrossam os cursos de EJA (Educação de Jovens e Adultos), perdendo a sua infância num espaço de silêncio muitas vezes irrecuperável.

De um modo geral, a mulher Surda é vista como incapaz para diversas atividades da vida diária, esta é uma postura que prevalece socialmente. Assim, como os espaços educacionais apresentam sérios problemas para as mulheres Surdas, a situação também se agrava nos espaços de saúde, como exemplo: a esterilização delas sem seu consentimento.

A comunidade, recentemente, despertou para trabalhar alguns aspectos de empoderamento, este referente, principalmente, ao reconhecimento de sua língua e de sua cultura. Tal feito é consolidado em várias universidades, entre elas se destaca a UFSC (Universidade Federal de Santa Catarina), pioneira nesse investimento social. A UFS (instituição onde trabalho atualmente) também, no ano de 2018, formou sua primeira turma de Licenciatura em Letras Libras. Nela se formaram duas alunas Surdas (e mais cinco alunos Surdos), que, na atualidade, estão prontas para o mercado de trabalho. Com esse contingente formado em várias universidades federais como resultado do projeto da Casa Civil - Viver sem limites, 2011-2014 - já temos mulheres Surdas em destaque como professoras em algumas instituições de nível superior nos setores públicos e privados.

$\mathrm{Na}$ contextualização da convocação a que fizemos alusão, alguns elementos foram apontados como primordiais para agenciar o empoderamento da mulher Surda. Na sequência, ressaltamos os referentes ao gênero e à educação da mulher Surda; à política em relação à ciência, à cultura e à comunicação, conforme recorte literal de Perlin e Vilhalva (2016, s/p):

a- Elementos para políticas referentes a gênero e educação da mulher surda

- acesso das mulheres surdas à educação bilíngue desde a creche ao ensino superior com professor bilíngue, intérpretes e livros traduzidos para língua de sinais;

- questões referentes ao gênero na educação de mulheres e meninas surdas com vistas a mudar a educação tradicional e a facilitar a participação com igualdade entre homem e mulher surdos.

b- Elementos para políticas: ciência, cultura e comunicação

- o acesso à educação: mulheres surdas na inclusão, conforme relatos, a abandonam por ser difícil;

- $\quad$ questões de feminismo a discutir entre as mulheres surdas, convidando a outras formas de pensamento e a revolucionar normas até aqui masculinas;

- a análise das tradições sociais, psicológicas e econômicas que governam o pensamento da maior parte das famílias, que influenciam particularmente a condição da mulher surda e o seu papel na sociedade, a fim de compreender as questões que afetam a condição e os papéis sociais desempenhados por homens e mulheres, bem como compreender esses movimentos e a implementação de melhorias para a situação das mulheres surdas nos países latino-americanos em que vivem;

- $\quad$ associação de mulheres surdas: como exemplo, as mulheres de terceira idade; 
- colocar vídeos com as informações em língua de sinais para as mulheres surdas no site da IV Conferência, bem como da Secretaria de Políticas para as Mulheres - Órgão do Governo.

Essas questões de vulnerabilidade de alguns grupos urgem ser discutidas por várias áreas, e nossa área das Letras não se nega a enfrentar esse debate e contribuir com ele. A ACD se mostra consolidada com trabalhos que contemplam essas demandas e aspectos teóricos que sustentam a discussão. Autores de renome assinalam esse compromisso, entre eles, apontamos Van Dijk (2003), que se posiciona no sentido de que devemos nos opor à desigualdade social. Desenvolvendo este ponto de vista, o mesmo autor, em obra de 2008, afirma que

A reflexão acerca do papel dos acadêmicos na sociedade e na polis transforma-se em uma parte inerente da tarefa proposta pela análise do discurso. Isso talvez signifique, entre outras coisas, que os analistas do discurso orientam suas pesquisas em solidariedade e cooperação com os grupos dominados (VAN DIJK, 2008, p. 114, itálico do autor, negrito nosso).

Assim, trabalhar com a comunidade Surda, pesquisar este grupo vulnerável, é minha resposta de solidariedade e cooperação, como analista crítica, comprometida com esse grupo que passou muito tempo de sua história dominado pela visão de mundo que nós ouvintes idealizamos.

\section{Abordagem Sociológica e Comunicacional do Discurso: foco na Socioanálise e na mudança social}

Considerando que a Abordagem Sociológica e Comunicacional do Discurso é uma abordagem no campo da ACD, criada por Pedrosa, destacamos Pedrosa (2012, 2014, 2016, 2018) como uma referência básica para se conhecer esta abordagem. Priorizaremos aqui apenas as contribuições necessárias às análises.

As narrativas de vida ou do eu são ricos materiais para seguir ou testar as hipóteses da socioanálise (BAJOIT, 2013), apresentando-as literalmente:

1. A prática das relacõos sociais, socializando o indivíduo, o incita a engajar-se num destino social.

2. O engajamento no seu destino social desperta nele expectativas relacionais de reconhecimento social e de realização pessoal: algumas são satisfeitas, outras são menos, ou não o são.

3. As expectativas satisfeitas formam o núcleo central da sua identidade; aquelas que são insatisfeitas alimentam tensões existenciais nas zonas periféricas dessa identidade.

4. Certas condições fragilizam a sua identidade e produzem mal-estares identitários que o incitam a questionar novamente o destino no qual ele está engajado.

5. O individuo constrói então uma narrativa do sujeito, pela qual ele explica para si mesmo o seu malestar identitário e projeta o que ele considera fazer para o aliviar.

6. Ele constrói as raz̃ões do sujeito: as suas motivações para passar ao ato e às resistências que se lhe opõem.

7. Ele implementa recursos psíquicos que enfraquecem as suas resistências e lhe permitem executar atos libertadores.

8. Ele passa ao ato: ele redefine mais ou menos profundamente as suas relações sociais... e ele paga o preço da sua libertação sempre parcial!

Quanto à contribuição da ASCD (PEDROSA, 2016, 2018) para os estudos em mudança social, será utilizada em diálogo com a Sociologia para a Mudança Social - SMS - (BAJOIT, 2006, 2009, 2013) e com a Sociologia Aplicada à Mudança Social - SAMS - (SACO, 2012).

Consoante Saco (2006), há três grandes etapas para identificarmos a dinâmica da mudança social: 1- iniciação à mudança: quando há identificação da mudança no sistema; 2- ação orientada à mudança: compõe-se de uma série de objetivos e estratégias que têm o objetivo de verificar os 
problemas estruturais que foram identificados; 3- transferência e consolidação da mudança: referese tanto ao reforço quanto à conservação das mudanças promovidas no sistema.

Ainda de acordo com a direção seguida, as mudanças podem ser: a) a partir de movimentos "de dentro para (endógena) \de fora para" (exógena) e b) mudanças a partir de movimentos "de cima para (descendente) $\backslash$ de baixo para (ascendente)".

Da SMS, a ASCD, com base nos trabalhos do sociólogo Bajoit (2008, p. 252, tradução nossa), apresenta as seguintes especificidades:

1. mudança das coações pelas quais se resolvem os problemas vitais da vida comum;

2. mudança dos princípios de sentido invocados para legitimar estas coações;

3. mudança das identidades coletivas que resultam da prática das relações sociais;

4. mudança das lógicas de gestão de si, pelas quais os indivíduos resolvem as tensões que atravessam essas identidades coletivas e constroem suas identidades pessoais;

5. mudança das lógicas de ação nas quais se comprometem, individual ou coletivamente.

Estas colocações teóricas serão o norte para, somando-se ao percurso metodológico, contribuir com a leitura crítica que pretendemos fazer nos discursos exemplificados no corpus da pesquisa, que, por sua vez, vão além de práticas discursivas, representam recortes das práticas sociais vivenciadas pela comunidade Surda.

\section{Percurso metodológico}

Como material de análise, selecionamos uma narrativa de vida do sujeito Surdo, coletada em 2013.2, semestre em que teve início, na UFRN (Universidade Federal do Rio Grande do Norte), o curso de Letras-Libras/Língua Portuguesa como $2^{\mathrm{a}}$ Língua. Antes de elaborar as narrativas, solicitei aos Surdos que preenchessem uma ficha que mapeava um pouco da ideia de pertencimento à comunidade Surda e dados socioeconômicos. Quanto aos textos introdutórios do Currículo Lattes, estes são facilmente acessados na página da plataforma do Conselho Nacional de Desenvolvimento Científico e Tecnológico - CNPq (http://lattes.cnpq.br/).

No que se refere à questão ética da pesquisa, elaboramos, para a primeira coleta, uma autorização de uso do material, respeitando-se o anonimato, que foi assinado pelos Surdos que participaram da pesquisa. Já o segundo texto, este é de acesso público.

Faremos uso de uma metodologia aplicada, qualitativa e sob a perspectiva interpretativista. O uso da análise linguística será com base em uma gramática descritiva, a Gramática SistêmicoFuncional (GSF), considerando que as análises em ACD devem se movimentar entre o linguístico e o social (WODAK; MEYER, 2003; FAIRCLOUGH, 2008; PEDROSA, 2013). As análises empíricas adotarão os métodos de extração (obtenção dos dados e sua organização) e de avaliação (regulação dos dados em informação) do objeto. Por sua vez, os dados serão formados a partir da coleta de narrativas de vida (BECK, 1997) de sujeitos surdos, de redação e de texto introdutório do Currículo Lattes. Nesse contexto, a análise percorrerá categorias que vão do linguístico ao social, mas enfatizando o evento social.

Halliday (2004) apresenta que a proposta de se estudar a língua conforme uma visão de uso e não de normas é baseada em três metafunções: ideacional, interpessoal e textual. Completando tal perspectiva, podemos entender, também nos trabalhos de Ghio e Fernandez (2005, p. 159), que as metafunções se localizam no nível da gramática (concepção de uso) e da semântica e que

essas três dimensões da estrutura semântica constroem a cláusula: Como representação: a cláusula constrói algum processo de experiência humana do mundo. Como intercâmbio: a cláusula implica uma transação entre falante e ouvinte ou audiência. Como mensagem: comunica uma determinada quantidade de informação (GHIO, FERNANDEZ, 2005, p. 79). 
No campo deste artigo, o foco será nos aspectos avaliativos das produções de mulheres Surdas, escritas em Língua Portuguesa. Deste modo, em termos gerais, estaremos trabalhando com a metafunção interpessoal. E a avaliatividade corresponde à maneira como usuários de uma língua, a partir de seu conhecimento linguístico (também em L2) e respeitando os contextos de cultura e situação, fazem uso dos recursos da língua (que tenha conhecimento, ou que tenha algum domínio, lembrando que estamos pensando nos Surdos escrevendo em língua Portuguesa como L2) para emitir avaliação (ALMEIDA, 2010; VIAN JR, 2010).

O sistema da Avaliatividade se estrutura a partir de três subsistemas: Atitude, gradação e engajamento. Já os três tipos de Atitude são: afeto (emoção), responsável pela expressão de sentimentos e de emoções; julgamento (ética), tipo de categorização utilizada para avaliar pessoas; e apreciação (estética), classificação usada para indicar a avaliação de coisas.

Identificamos nos escritos de Halliday (2004, p. 55) que uma gramática/Linguística como a que ele propunha considerava que deveríamos entender que "a linguagem varia, de acordo com o usuário e de acordo com as funções que cumpre"; também "compreender a relação entre língua e cultura e entre linguagem e situação"; e entre suas colocações está que um tipo de gramática como a que ele desenvolveu ajuda a "compreender a linguagem de sinais dos surdos".

\title{
4 Mulheres surdas, práticas de resistências e construção da identidade interseccional: uma análise crítica dos discursos de lutas em sua educação
}

O tópico anterior traz um quadro resumido do que seja o desafio da mulher Surda em relação à sua educação e outros aspectos da vida social. Relatos de abandono dos bancos escolares são muitos. Como continuar estudando se sua língua não é respeitada e ensinada nas escolas? Como continuar estudando se, muitas vezes, não há intérpretes? Como conseguir estudar sem ter uma língua? Abaixo, vamos trabalhar dois tipos de gêneros, a saber, narrativas de vida e texto introdutório do Currículo Lattes, mas, principalmente, dois textos em que, em seu discurso, identificamos as práticas de resistências da mulher Surda e sua identidade interseccional.

Crenshaw $(2017, \mathrm{~s} / \mathrm{p})^{4}$ assinala que as mulheres têm se organizado contra as "violências quase rotineiras que moldam suas vidas", pois verificaram que, quando as experiências são compartilhadas, as vozes adquirem mais força política que a voz solo. Elas têm também identificado, assim como outros grupos vulneráveis, que "a política baseada na identidade tem sido uma fonte de força [...] e desenvolvimento intelectual". Assim se expressa a jurista americana e professora de Direito com experiência em várias universidades americanas, incluindo Harvard:

\begin{abstract}
A inclusão da política de identidade, no entanto, tem estado em tensão com as concepções dominantes de justiça social. Raça, gênero e outras categorias de identidade são tratados com maior frequência no discurso liberal dominante como vestígios de preconceito ou dominação-isto é, como estruturas intrinsecamente negativas nas quais o poder social trabalha para excluir ou marginalizar aqueles que são diferentes (CRENSHAW, 2017, s/p).
\end{abstract}

Seguir este raciocínio para interseccionar o "ser mulher" e o "ser Surda" pode ser uma perspectiva producente para o objetivo que propomos atingir neste estudo.

Vejamos os exemplos discursivos:

a- Narrativas de vida

1- A vida hoje é difícil pra tudo, mas temos que enfrentar esse desafio pra sobreviver na sociedade que tem preconceito com deficiente, mas é possível conquistar tudo que deseja com força de vontade. A minha vida na escola foi muito difícil porque fui excluída na sala por amigos e professores por tem dificuldade de aprendizagem e só conseguir aprender

\footnotetext{
4 O texto original em inglês é de 1993, e sua tradução para a Língua Portuguesa por Carol Correia é de 2017.
} 


\begin{abstract}
a ler e escrever porque minha mãe pagou uma aula particular, então acredito que nem toda família tem condições de pagar uma aula por fora.

Atualmente curso ciências contábeis por vocação e vontade de tem uma carreira fixa e letras libras para mostrar que os surdos são capazes tem aprenderem e basta os professores oferecerem uma educação especial (UFRN, Letras-Libras/Língua Portuguesa como $2^{\text {a }}$ Língua, agosto 2013).
\end{abstract}

Beck (1997) afirma que os sujeitos são construídos por meio de interações discursivas, ou seja, através de narrativas de vida ou do eu. O pensamento narrativo é a fonte pela qual o sujeito confere sentido à sua própria experiência porque ele é constituído discursivamente. Sua vida, em última instância, é uma interpretação ou compreensão de si mesmo. Esteban (2006) defende a tese de que a narrativa tem um papel decisivo de intermediar os mundos da cultura e do indivíduo, de seus valores, de suas crenças e de suas esperanças.

Através da denominada cognição narrativa e suas escolhas de "conceitualização", os sujeitos se expressam das mais variadas maneiras, seja por finais tristes, ou mesmo pelos absurdos nos quais suas histórias se firmam - "A vida hoje é difícil pra tudo, mas temos que enfrentar esse desafio pra sobreviver na sociedade que tem preconceito com deficiente". Como podemos seguir na narrativa acima, resgatamos "a voz do sujeito" por meio de várias interpretações que ele faz de si mesmo, ou da leitura de mundo que ele faz. Como diz Ricouer (2013, p. 02), "o conhecimento de si próprio é uma interpretação". Identifiquemos outras interpretações que o sujeito faz de sua vida: "tem dificuldade de aprendizagem"; "só conseguir aprender a ler e escrever porque minha mãe pagou uma aula particular"; "acredito que nem toda família tem condições de pagar uma aula por fora". As narrativas sobre si mesmo são, assim, uma maneira de fazer frente a seu mal-estar identitário (BAJOIT, 2008) ou de fazer frente à sua identidade narrativa. Trata-se de uma forma também de avaliar não só suas emoções, como também as experiências ou pessoas. Vejamos como suas emoções e seus sentimentos (subsistema Afeto) foram expressos: "é possível conquistar tudo que deseja com força de vontade"; "fui excluída na sala por amigos e professores". E há também avaliações negativas quanto às coisas (Apreciação) e às pessoas (Julgamento), respectivamente: "sociedade que tem preconceito com deficiente"; "fui excluída na sala por amigos e professores".

O sociólogo Bajoit (2013, s/p) classifica alguns tipos de narrativas: narrativas de compreensão e narrativas de alívio. Nas narrativas de compreensão, o sujeito objetiva, diante do que lhe aconteceu, dar sentido. Já as narrativas de alívio classificam-se em: de avaliação, de desistência, de compensação ou de perseverança. Nas palavras do próprio autor: "o indivíduo avalia a importância do seu mal-estar e pode então considerar desistir de satisfazer as expectativas relacionais com as quais se sente frustrado, de compensar a insatisfação de uma pela satisfação da outra ou de perseverar no seu esforço para obter o que ele espera".

Classificamos a narrativa em análise como de perseverança (subclassificação da narrativa de alívio). O sujeito persevera no seu esforço, mesmo diante de tantos desafios quase insuperáveis, na sua voz: "mas é possível conquistar tudo que deseja com força de vontade"; "Atualmente curso ciências contábeis por vocação e vontade de tem uma carreira fixa e letras libras para mostrar que os surdos são capazes tem aprenderem".

Claramente se identificam suas práticas de resistência, construindo, assim, sua identidade cidadã e, ao mesmo tempo, sua identidade interseccional. O fato de ser mulher e ser Surda se soma à sua resistência, à sua luta para conseguir o que o sistema educacional lhe nega. As violências simbólica e física em relação à educação ("fui excluída na sala por amigos e professores por tem dificuldade de aprendizagem") são moldadas por outras dimensões sociais, fazendo-a acreditar que é ela que tem dificuldade de aprendizagem e não que a escola não está preparada para recebê-la. Isso ocorre também "Por causa de sua identidade interseccional como mulheres" (CRENSHAW, 
2017, s/p) ${ }^{5}$ e como Surdas são moldadas dentro de discursos machistas e dentro de discursos ouvintistas.

Prosseguindo o estudo pelos caminhos da Socioanálise, observa-se que, em sua narrativa de vida, indicada pela hipótese 5 (h.5), o sujeito, mesmo estando inserido em "um destino social" (h 1), é capaz de questionar sua situação, despertando nela expectativas relacionais de reconhecimento social e/ou de realização pessoal e confrontando sua situação social, a fim de suplantar seu mal-estar identitário - "A minha vida na escola foi muito difícil porque fui excluída na sala por amigos e professores por tem dificuldade de aprendizagem" (h 2, 3 e 4); assim, constrói as motivações para vencer e passar aos atos de libertação das amarras de injustiças, ainda que tenha que pagar um preço por sua vitória - "Atualmente curso ciências contábeis por vocação e vontade de tem uma carreira fixa e letras libras para mostrar que os surdos são capazes tem aprenderem" (h 6,7 e 8$)$.

O próximo exemplo, a seguir, é o texto introdutório do Currículo Lattes de uma professora universitária:

\begin{abstract}
b- Texto introdutório do Currículo Lattes ${ }^{6}$
KLS Endereço para acessar este CV: http://lattes.cnpq.br/6652911914719737. Última atualização do currículo em: 02/12/20187.

2- Durante quase 25 anos eu trabalhei como professora de surdos em escolas de surdos na cidade de Curitiba-Pr e por 10 anos fiz parte de equipe pedagógico de DEE/SEED (Secretaria de Educação do Paraná). Doutora na área de educação em Universidade Federal de Santa Catarina UFSC (bolsista CNPq), formada em pedagogia da UTP (Universidade Tuiuti do Paraná) e com especialização em área de surdez. Autora do livro: As imagens do outro sobre a cultura surda\&quot; editora UFSC, Florianópolis, $1^{\text {a }}$ ed. 2008, $2^{\text {a }}$ ed. 2009 e $3^{\text {a }}$ ed. 2014. (...) Atualmente faço parte de equipe de Letras/Libras da UFSC como professora das disciplinas; Fundamentos de Educação dos Surdos; História de Educação dos Surdos; Metodologia de ensino de Libras como Língua 1; Metodologia de ensino de Literatura surda e outras disciplinas afins e também assumi a coordenação geral de Letras Libras desde 2013. Tenho experiência com ênfase em Educação, atuando principalmente nos seguintes temas: língua de sinais, educação, surdos, lingüística e metodologia de língua de sinais. Como mulher surda que também protagonizou muito dos momentos históricos que são resgatados durante a trajetória de vida, tanto como surda quanto profissional da área, pretendo realizar muitos projetos que retrate positivamente e vitoriosamente em prol aos movimentos surdos!
\end{abstract}

Aos comentários e à análise do texto do currículo anteriormente mostrado, acrescentaremos trechos de uma entrevista com a Profa. Dra. Karin Strobel. ${ }^{8}$

No início do texto introdutório do currículo, identificamos que, desde a década de 1990, uma média de 3 anos após concluir o ensino médio, KLS é ativista em relação à causa Surda (vejamos o que ela diz na entrevista: "Contato com a Feneis se iniciou em 1994, quando o expresidente Antonio Campos me convidou para fazer parte da chapa dele como diretora vicepresidente dos Profissionais da Área e depois como fundadora e diretora regional do escritório Feneis-PR".). Não obstante, sua "iniciação à mudança", nos termos de Saco (2006), acontece na adolescência quando entra em contato com a sua língua materna, a Libras ("O meu primeiro contato com a língua de sinais aconteceu na adolescência, com quinze anos"). Seguem suas outras práticas de resistências com ações - trabalho, estudos, publicações na área da surdez, orientadas à mudança, ao direcionar sua capacidade intelectual para a comunidade Surda.

\footnotetext{
${ }^{5}$ A autora trata de ser mulher e de ser negra, o que contextualizamos com a ideia do nosso estudo.

${ }^{6}$ Currículo Lattes está registrado na plataforma http://lattes.cnpq.br/.

${ }^{7} \mathrm{Em}$ alguns trechos, estamos utilizando sigla para o nome da professora, mas não há problemas éticos na pesquisa, considerando-se que o CV lattes é público.

${ }^{8}$ Entrevista com Karin Lilian Strobel disponível em: https://www.editora-arara-azul.com.br/revista/03/perfil.php. Acesso em: 12 out. 2018.
} 
Ela mesma confirma sua participação nas mudanças sociais quando diz: "Como mulher surda que também protagonizou muito dos momentos históricos que são resgatados durante a trajetória de vida". Aqui, muito mais do que a avaliatividade, podemos apontar a transitividade da GSF. Os processos verbais são destaque. O processo verbal material "protagonizou" aponta para uma escolha lexical que revela um sujeito que está à frente de ações de mudanças para si e para sua comunidade. Podemos indicar que várias das mudanças em melhoria para o povo Surdo, como leis e decretos, vieram em resposta a movimentos de "dentro para fora" (endógenos) e de "baixo para cima" (ascendentes).

Analisando as mudanças com base na proposta do sociólogo Bajoit, podemos acompanhar como "as mudanças das identidades coletivas que resultam da prática das relações sociais" afetam a vida e as construções das identidades individuais". Em informações advindas da entrevista já indicada, diz Strobel (informação verbal):

\footnotetext{
uso minhas próprias experiências da infância não somente como aluna surda, sim como "ser surda" para lutar pelo povo surdo o direito de nós escolhermos a língua e de construção de identidades sem a imposição "normalizadora" da sociedade que impõe aos sujeitos surdos que sejamos "normais", isto é, que falemos e ouçamos para que sejamos aceitos na vida social. Hoje me considero uma adulta guerreira da vida com um corpo surdo mais forte com uma ancoragem positiva de identidade surda.
}

A quase "consolidação da mudança" pode ser identificada em um fragmento de sua entrevista: "Pelo que tenho observado até agora pelas políticas públicas brasileira na área da educação dos surdos, percebo que os caminhos nesta área está bem encaminhada". Indicamos "quase" porque julgamos que ainda há um caminho a percorrer, fato que pode ser corroborado com as palavras com que a professora encerra sua entrevista: "Surdos, sejam persistentes e nunca desistam dos seus sonhos, arregacem as mangas e vão à luta com toda a coragem... Não deixem as pessoas dizerem a vocês: "vai ser difícil vocês conseguirem" ou "vocês não podem fažer...", se é algo que vocês querem, acreditem em si mesmos e vão à frente! Lembrem-se: "Não há vitória sem luta e não há luta sem coragem". Esta fala facilmente pode ser reportada ao primeiro texto exemplificado: "A vida é difícil pra tudo". Difícil para o "ser mulher", para o "ser Surda".

Temas como esses precisam ser abordados, considerando que, na maioria das vezes, se não todas, as estratégias políticas "ignoram ou suprimem as questões interseccionais", ou seja, "as leis abordam um caso ou outro, e nunca juntos" (CRENSHAW, 1993, s/p). As leis, os decretos ou outros dispositivos do governo são tratados separadamente, de maneira estanque, por exemplo, abordam o "ser mulher" e o "ser Surda", separadamente; portanto, constituem-se como duas lutas a serem travadas e vencidas.

\section{Conclusão: "Não deixem as pessoas dizerem a vocês: 'vai ser difícil vocês conseguirem" ou 'vocês não podem fazer..."'}

As frases que formam o título da conclusão poderiam ser tomadas como impeditivas na vida da mulher Surda; contudo, por algumas histórias e pelo conhecimento de mulheres surdas como professoras universitárias, felizmente para estas a barreira foi derrubada; porém, para outras, as mudanças ainda precisam ser vividas.

Do ponto de vista deste estudo, trabalhar a interseccionalidade, de ser mulher Surda, pode ser muito benéfico como mediação da tensão que possa existir nas asserções de identidades múltiplas, o que exige uma contínua política da coletividade (CRENSHAW, 2017). Construir esse significado socialmente é de relevância política sem precedentes. Como prossegue a jurista, "é importante notar que a identidade continua a ser um local de resistência para membros de diferentes grupos subordinados" (idem, s/p) e que as identidades, não podemos negar, são constituídas por meio de múltiplas dimensões, isso porque, às tratadas aqui ("ser mulher" e "ser 
Surda"), poderiam se somar outras, como "ser negra", "ser pobre", "ser nordestina", por exemplo. Faz-se necessário, então, que "as políticas de identidade ocorram no local onde as categorias se cruzam", defende Crenshaw (2017, s/p).

Não é sem retornos, sociais e acadêmicos, que a ACD se compromete e se solidariza com grupos vulneráveis, a exemplo da pesquisa promovida neste texto. Com efeito, responder a essa demanda social é um dos contundentes objetivos políticos da Análise Crítica do Discurso.

\section{REFERÊNCIAS BIBLIOGRÁFICAS}

ALMEIDA, F. S. D. P. Atitude: afeto, julgamento e apreciação. In: VIAN JR, O.; SOUZA, A. A.;

ALMEIDA, F. S. D. P. (Orgs.). A linguagem da avaliação em língua portuguesa: estudos sistêmico-funcionais com base no Sistema de Avaliatividade. São Carlos/SP: Pedro \& João Editores, 2010.

BAJOIT, Guy. Vers une théorie socio-analytique de la relation sociale / Para uma teoria socioanalítica da relação social. Tradução de Marcos Tindo. Texto cedido gentilmente, por e-mail, pelo autor, 2013.

La tiranía del "grand ISA". Cultura y representaciones sociales. Ano 3, n. 6, p. 9-24, março de 2009. Disponível em: www.culturayrs.org.mx/revista/.../Bajoit.HTML. Acesso em: 09 out. 2018.

El cambio social, análisis sociológico del cambio social y cultural en las sociedades contemporáneas. Madrid: Siglo, [2003] 2008.

Tudo muda: proposta teórica e análise da mudança sociocultural nas sociedades ocidentais contemporâneas. Lisboa, Portugal: Unijaí, 2006.

BECK, U. A reinvenção da política: rumo a uma teoria da modernização reflexiva. Cap. 1. In:

GIDDENS, A.; BECK, U.; LASH, S. Modernização reflexiva: política, tradição e estética na ordem social moderna. São Paulo: Editora da UNESP, 1997.

CRENSHAW, Kimberlé Williams. Mapeando as margens: interseccionalidade, políticas de identidade e violência contra mulheres não-brancas / Mapping the margins: intersectionality, identity politics, and violence against woman of color. Tradução de Carol Correia. 2017. Disponível em: $\quad$ https://www.geledes.org.br/mapeando-as-margens-interseccionalidade-politicas-deidentidade-e-violencia-contra-mulheres-nao-brancas-de-kimberle-crenshaw $\% \mathrm{E} 2 \% 80 \% 8 \mathrm{~A}$ -

$\% \mathrm{E} 2 \% 80 \% 8$ Aparte-1-4/. Original disponível em: https:// negrasoulblog.files.wordpress.com/2016/04/mapping-the-margins-intersectionalityidentity-politics-and-violence-against-women-of-color-kimberle-crenshaw1.pdf. Acesso em: 06 mar. 2019.

ESTEBAN, J. G. La formación de sujetos sociales y el aprendizaje ciudadano. In: ESTEBAN, J. G. et al. Estructura tiempo y sujeto: nuevos recursos para la discusión interdisciplinaria. Bogotá: Universidad Distrital Francisco José de Caldas, 2006.

FAIRCLOUGH, Norman. Discurso e mudança social. Brasília: Editora Universidade de Brasilia, [2001] 2008.

FONTANA, Mónica G. Zoppi; FERRARI, Ana Josefina. Apresentação: uma análise discursiva das 
identificações de Gênero. In: FONTANA, Mónica G. Zoppi; FERRARI, Ana Josefina (Orgs.). Mulheres em discurso: identificação de gênero e práticas de resistência. Vol. 2. São Paulo: Pontes, 2017. p. 07-20.

GHIO, Elsa; FERNÁNDEZ, María Delia. Manual de linguística sistémico funcional: el enfoque de M. A. K. Halliday \& R. Hasan - aplicaciones a la lengua española. Santa Fé: Universidad Nacional del Litoral, 2005.

HALLIDAY, M. A. K. An introduction to Functional Grammar. Revisão de Christian M. I. M. Matthiessen. 3. ed. London: Edward Arnold, 2004.

MOUGEOLLE, Léa. O conceito de “interceccionalidade". 2015. Disponível em: http://www.sociologia.com.br/o-conceito-de-interseccionalidade/. Acesso em 05 mar. 2019.

NORONHA, Raquel. A mulher no discurso empresarial na mídia. In: FONTANA, Mónica G. Zoppi; FERRARI, Ana Josefina (Orgs.). Mulheres em discurso: identificação de gênero e práticas de resistência. Vol. 2. São Paulo: Pontes, 2017. p. 23-41.

PERLIN, Gladis; VILHALVA, Shirley. Mulher Surda: elementos ao empoderamento na política afirmativa. Revista Forum - INES, Rio de Janeiro, n. 33, 2016. Disponível em: http:/ www.porsinal.pt/index.php?ps $=$ artigos\&idt $=$ artc\&cat $=27 \& i d a r t=453$. Acesso em: 09 out. 2018.

PEDROSA, Cleide Emília Faye. Análise crítica do discurso: pesquisas e contribuições sociais. In: RAMALHO, Christina Bielinski; LIMA, Geralda de Oliveira Santos. Estudos linguísticos e literários: edição comemorativa 10 anos do Programa de Pós-graduação em Letras da UFS. Aracaju: Editora Criação, 2018. p. 153-178.

Análise crítica do discurso e a proposta da corrente nacional: da abordagem às primeiras pesquisas. In: KALLARRARI, Celso; BESSA, Décio; PEREIRA, Aline Santos (Orgs.). Estudos linguísticos e formação docente. São Paulo: Pontes, 2016.

Abordagem sociológica e comunicacional do discurso, uma proposta para fazer análise crítica do discurso. In: SÁ JÚNIOR, Lucrécio Araújo de; BARBOSA, Tatyana Mabel N. Práticas discursivas e ensino de língua(gens). Natal: Edurfrn, 2014. p. 15-58.

A Socioanálise e a Abordagem Sociológica e Comunicacional do Discurso: caminhos de análise em Análise Crítica do Discurso. Trabalho apresentado na mesa-redonda da ABRALIN: Análise Crítica do Discurso e os caminhos de análise. VIII Congresso Internacional da Associação Brasileira de Linguística. Natal: UFRN, 30/01 - 02/02/2013.

Abordagem Sociológica e Comunicacional do Discurso (ASCD): uma corrente para fazer Análise Crítica do Discurso. PARTE 1: Herança teórica da Sociologia (Aplicada) para a Mudança Social. Natal: UFRN, 2012. Texto fundador. Disponível em: www.ascd.com.br. Acesso em: 12 out. 2018.

RESENDE, Viviane de Melo. Análise de Discurso Crítica: reflexões teóricas e epistemológicas quase excessivas de uma analista obstinada. In: ; REGIS, Jacqueline Fiuza da Silva (Orgs.). Outras Perspectivas em Análise de Discurso Crítica. São Paulo: Pontes, 2017. p. 11-51. SACO, A. Sociología Aplicada al Cambio Social. Madrid, España: Andavira, 2006. 
STROBEL, K. L. Mulheres Surdas que fazem História. Revista da FENEIS, n. 32. Disponível em: https://issuu.com/historiadesurdos.blogsp.com/docs/revfeneis32. Acesso em: 13 jun. 2016.

VAN DIJK, T. Discurso e poder. Judith Hoffnagel e Karina Falcone (Orgs.). São Paulo: Contexto, 2008.

La multidisciplinaridad del análisis crítico del discurso: un alegato en favor de la diversidad. In: WODAK, Ruth; MEYER, Michael (Orgs.). Métodos de Análisis Crítico del Discurso. Barcelona: Gedisa, 2003. p. 143-178.

VIAN JR, Orlando. O sistema de avaliatividade e a linguagem de avaliação. In: VIAN JR, O.; SOUZA, A. A.; ALMEIDA, F. S. D. P. (Orgs.). A linguagem da avaliação em língua portuguesa: estudos sistêmico-funcionais com base no Sistema de Avaliatividade. São Carlos, SP: Pedro \& João Editores, 2010. p. 19-30 